\title{
Assessment of drivers of forest changes using multi-temporal analysis and boosted regression trees model: a case study of Nyeri County, Central Region of Kenya
}

\author{
Authors: Nancy Mwangi, $\underline{\text { Hunja Waithaka, Charles Mundia, Mwangi Kinyanjui \& Felix Mutua }}$
}

Modeling Earth Systems and Environment

\begin{abstract}
The Central Region of Kenya has undergone significant changes in land cover due to a broad range of drivers. These changes are more pronounced in forestland conversions. Past researches within the study area have identified drivers of land cover change without quantifying the influence of these drivers. Predictor variables include population density, precipitation, elevation, slope, forest fires, soil texture, proximity to roads, rives and towns. Land cover changes were analyzed using multi-temporal land cover maps between year 1990 and 2014. Boosted regression trees model was applied to determine the significant drivers and quantify their relative influence on key forestland transitions. The local and spatial influence of the drivers has further been analyzed by geographical weighted regression using coefficients determined at each sample point. Significant land cover changes continuously occurred over the study period. Forestland reduced from $38.90 \%$ in 1990 to $38.14 \%$ in 2014. Grassland reduced from 32.59 to $22.57 \%$, cropland increased from 28.05 to $38.83 \%$ and wetland changed from 0.07 to $0.04 \%$. Other land which constitutes of bare land and built up increased from 0.38 to $0.42 \%$. The results show population density had the highest contribution to forestland changes throughout the study period, with a minimum contribution of $20.02 \%$ to a maximum of $26.04 \%$. Other significant variables over the study period are precipitation, slope, elevation and the proximity variables. The results indicate that the relative influence of the drivers to forestland conversion varies with time, location and type of transition.
\end{abstract}

\section{Funding}

This study was part of System for Land-based Emissions Estimation in Kenya (SLEEK) Project, funded by the Australian Government in partnership with the Government of Kenya.

\section{Author information}

Affiliations

1. Department of Geomatic Engineering and Geospatial Information Systems (GEGIS), Jomo Kenyatta University of Agriculture and Technology (JKUAT), P.O. Box 62000, Nairobi, 00200, Kenya 
- Nancy Mwangi

- Hunja Waithaka

- Felix Mutua

2. Institute of Geomatics, GIS and Remote Sensing (IGGReS), Dedan Kimathi University of Technology, P.O. Box 657, Nyeri, 10100, Kenya

- Charles Mundia

3. Department of Natural Resources, Karatina University, P.O. Box 1957, Karatina, Kenya

○ Mwangi Kinyanjui 